\title{
Surface-Enhanced Raman Scattering Microspectroscopy Enables the Direct Characterization of Biomineral-Associated Organic Material on Single Calcareous Microskeletons
}

\author{
Alessandro Silvestri, Jürgen Pätzold, Peter Fratzl, André Scheffel,* and Damien Faivre*
}

Cite This: J. Phys. Chem. Lett. 2020, 11, 8623-8629

Read Online

ACCESS | 岁 Metrics \& More 回 Article Recommendations

ABSTRACT: Biominerals are composite materials with inorganic and organic components. The latter provide insights into how organisms control mineralization and, if derived from micro/nannofossils, into past climates. Many calcifying organisms cannot be cultured or are extinct; the only materials available for their study are therefore complex environmental samples in which the organism of interest may only be a minor component. There is currently no method for characterizing the biomineral-associated organic material from single particles within such assemblages, so its compositional diversity is unknown. Focusing on coccoliths, we demonstrate that surface-enhanced Raman scattering microspectroscopy can be used to determine the origin and composition of fossil organic matter at the single-particle level in a heterogeneous micro/nannofossil assemblage. This approach may find applications in the study of micro/nannofossil assemblages and uncultivated species, providing evolutionary insights into the macromolecular repertoire involved in biomineralization.

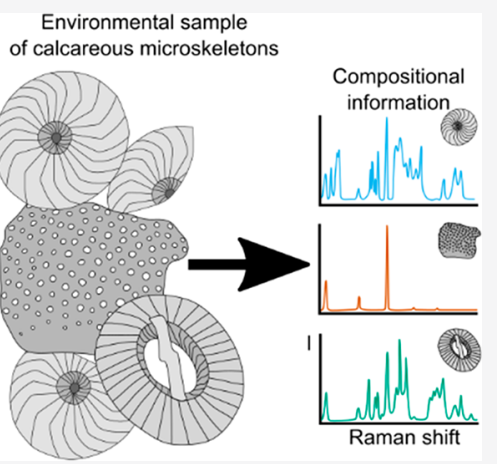

ingle-celled organisms produce a wide variety of complex$\checkmark$ shaped calcium carbonate-based microskeletons using specific sets of macromolecules, which usually become embedded within the mineral phase during its formation. ${ }^{1-3}$ Knowledge of the skeleton-embedded organic material is crucial for (1) understanding how the variety of skeleton architectures is achieved, which is of interest in the context of biomimetic materials chemistry and evolutionary developmental biology, (2) understanding why skeletons of some species make it to the ocean floor while those of others undergo complete dissolution, which is of interest in the context of marine ecosystem biology and the biogeochemical cycle of carbon, and (3) the interpretation of biochemical data from micro/nannofossils in the context of paleoclimate reconstruction. ${ }^{4-10}$ The obstacles for filling these knowledge gaps are that the skeletons of most species can be obtained exclusively from the environment, either in small amounts or in heterogeneous assemblages, and that suitable approaches for single-skeleton organic matrix analysis are lacking. Biochemical approaches are usually not applicable, as they require calcareous structures in quantities of a milligram or more. This high material requirement is due to the fact that the loss of certain amounts of organic material after its release from the mineral during sample preparation is unavoidable. For most single-celled calcifiers, however, skeletal material can be obtained exclusively from the environment and usually only in small quantities or as heterogeneous assemblages. ${ }^{11}$ Calcareous micro/nannofossil sediments, as an example of an environmental microskeleton sample, usually contain material of different taxa, making it challenging to assign biochemical data from bulk sample analysis to a specific taxon. ${ }^{9,12}$ Size fractionation approaches can reduce the species heterogeneity of the samples but yield, at best, near single species assemblages, leaving doubts about the true origin of the organic material. ${ }^{9,13-15}$ A microscopyassisted spectroscopic approach could resolve these doubts but is presently lacking.

Raman microspectroscopy can characterize and identify organic and inorganic phases at the submicrometer scale, ${ }^{16-19}$ making it an attractive tool for the analysis of samples that are not suited for biochemical analyses, such as calcareous micro/ nannofossil assemblages. However, with classical Raman microspectroscopy, the organic components of calcareous microskeletons usually cannot be detected because the corresponding Raman signal is orders of magnitude weaker than that of the mineral phase.

Here we establish a method for studying single microskeletons that preserves the specimen and provides information about the biomineral-associated organic material. Focusing on coccoliths, which are the calcitic scales of single-celled coccolithophorid algae ${ }^{20}$ and prime components of calcareous micro/nannofossil sediments as well as interesting models in the context of biomimetic materials chemistry, we demonstrate that surface-enhanced Raman

Received: July 3, 2020

Accepted: September 22, 2020

Published: September 22, 2020

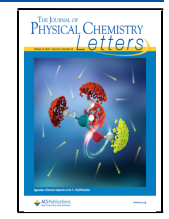


scattering (SERS) microspectroscopy but not classical Raman microspectroscopy can detect the organic material tightly associated with a single coccolith. We demonstrate the value of the SERS microspectroscopy approach with mixed-species micro/nannofossil samples, where we acquired biochemical information from coccoliths of Calcidiscus species and coexisting fragments of foraminifera skeletons individually, without separating them from each other and other calcareous particles contained in the $\sim 470000$ years (470 ka) old calcareous raw material. Our study shows that SERS microspectroscopy closes a gap in the repertoire of approaches for characterizing complex environmental samples of calcareous microskeletons, providing a tool for characterizing mineral-associated organic material at the single-particle level.

Our search for a method to characterize the organic matrix of single calcareous microskeletons started with conventional Raman microspectroscopy and isolated coccoliths of the coccolithophores Pleurochrysis carterae. We chose this species because of the possibility of comparing and validating the spectroscopic results with biochemical information about the coccolith-associated organic matrix, which for coccolithophores are most comprehensively available for this species. ${ }^{5,21}$ The conventional Raman spectra acquired from dried, isolated P. carterae coccoliths show five peaks (Figure 1a,d). Peak assignment revealed these to exclusively originate from the $\mathrm{CaCO}_{3}$ part of the coccoliths. Increasing the laser power (1$20 \mathrm{~mW})$ and acquisition time $(1-100 \mathrm{~s})$ did not give rise to additional peaks (Figure S1), suggesting (i) the organic material was absent or (ii) organic material concentrations were below the detection limit. To test for the presence of organic material, we dissolved the $\mathrm{CaCO}_{3}$ phase by suspending the coccoliths in an EDTA solution, which dissolves the $\mathrm{CaCO}_{3}$ and frees $\mathrm{CaCO}_{3}$-associated organic material, and separated the $\mathrm{H}_{2} \mathrm{O}$-soluble and insoluble material by centrifugation. Raman analysis of both fractions yielded spectra that were significantly more complex than those of whole coccoliths (Figure 1d). The spectra of the soluble fraction show peaks characteristic of polysaccharides $(825,872$, and $1088 \mathrm{~cm}^{-1}$ ) and carboxylate groups (1420 and $\left.1730 \mathrm{~cm}^{-1}\right)$, and those of the insoluble fraction show peaks characteristic of proteins $\left(537,609,643,1003,1228\right.$, and $\left.1650 \mathrm{~cm}^{-1}\right)$ and polysaccharides $\left(894 \mathrm{~cm}^{-1}\right)$, including cellulose $\left(1071 \mathrm{~cm}^{-1}\right)$. The compositional nature of the soluble fraction extracted from the Raman spectra is in agreement with the result of our sodium dodecyl sulfate-polyacrylamide gel electrophoresis (SDS-PAGE) analysis and previous work, showing acidic polysaccharides to be the major soluble macromolecular constituents of the organic matrix of $P$. carterae coccoliths (Figure $1 \mathrm{~b}){ }^{21}$ The compositional nature of the insoluble fraction extracted from the Raman spectra is in agreement with the published data on the base plates of $P$. carterae coccoliths, ${ }^{5}$ which have been isolated here (Figure 1c). The conclusion from these results is that conventional Raman microspectroscopy lacks the necessary sensitivity to detect the organic matrix when applied to whole coccoliths.

Facing insufficient sensitivity with conventional Raman microspectroscopy, we tested SERS microspectroscopy because the SERS effect is known to enhance the Raman scattering of organic molecules by several orders of magnitude. ${ }^{22,23}$ SERS has been employed for single-bacterial and -algal cell analyses, and the detection of various molecules down to the single-molecule level, but not for the study of calcareous skeletons. $^{24,25}$ We induced the nucleation of silver
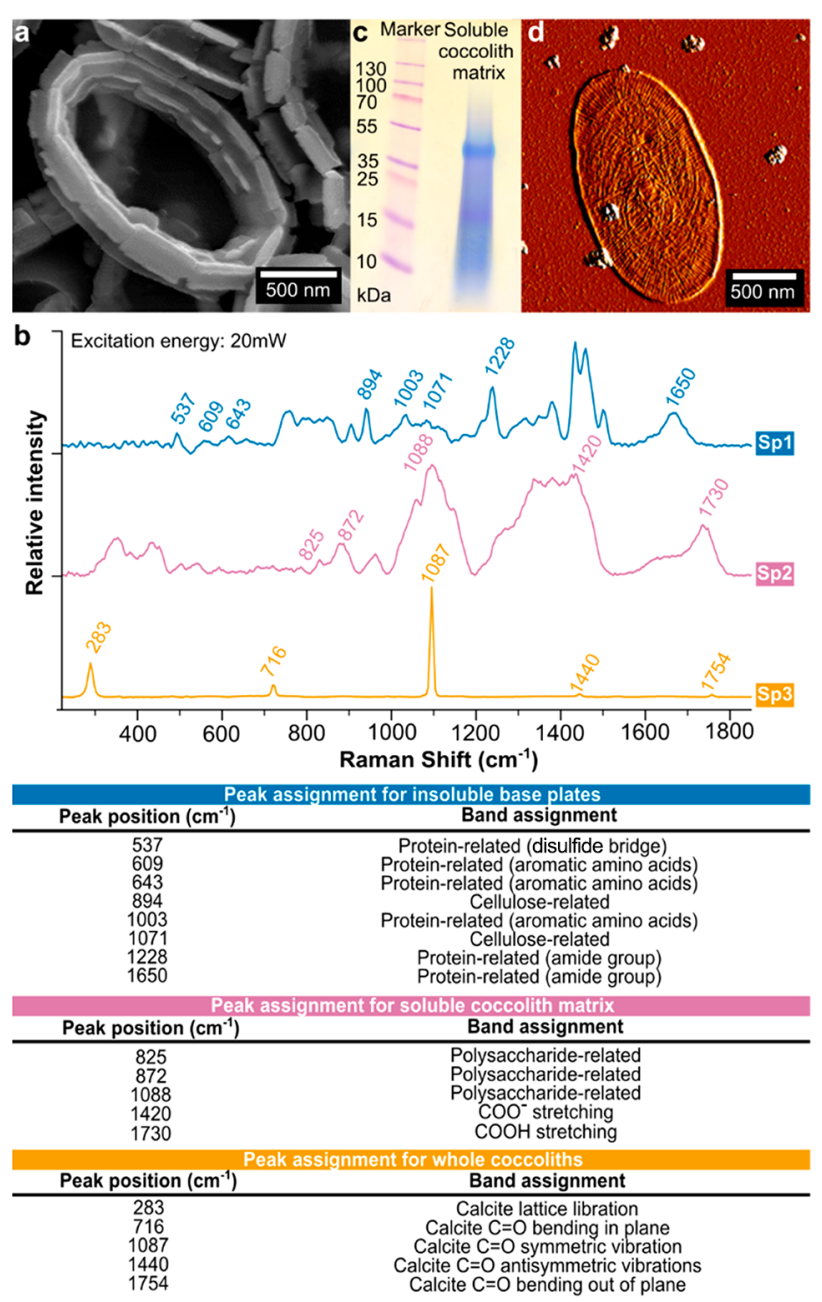

Figure 1. Conventional Raman microspectroscopy is inadequate for characterizing the organic matrix of whole coccoliths. (a) Scanning electron microscopy micrograph of isolated coccoliths from $P$. carterae. (b) Averaged Raman spectra of whole coccoliths (Sp1), the isolated soluble organic matrix ( $\mathrm{Sp} 2)$, and isolated coccolith base plates ( $\mathrm{Sp} 3$ ) and assignment of the Raman peaks. The spectra were recorded at various positions on dry coccolith powder. The spectrum of whole coccoliths shows peaks characteristic of calcite and lacks peaks representing organic matter. Dissolution of the coccolith calcite yields the insoluble base plates and the soluble organic matrix, which have been separated by centrifugation. For detailed information about the peak assignments, see Tables S1 and S2. (c) SDS-PAGE analysis of the soluble organic coccolith matrix stained with the cationic dye StainsAll. The staining pattern matches that of the soluble acidic polysaccharides known to be tightly associated with $P$. carterae coccoliths. (d) Atomic force microscopy amplitude-contrast micrograph of a coccolith base plate $\left(\mathrm{H}_{2} \mathrm{O}\right.$-insoluble $)$ isolated after dissolution of the coccolith calcite.

nanoparticles (AgNPs) on the surface of isolated P. carterae coccoliths (Figure 2a). Briefly, coccolith powder was suspended and incubated in a freshly prepared $\mathrm{NaBH}_{4}$ solution and after $1 \mathrm{~min}$ pelleted and washed with ultrapure water. Upon resuspension in a $\mathrm{AgNO}_{3}$ solution, the reducing agents $\left(\mathrm{BH}_{4}^{-}\right.$anions and $\mathrm{H}_{2}$ generated by the reaction of $\mathrm{BH}_{4}^{-}$with water) adsorbed on the coccolith surface rapidly reduced silver cations, forming AgNPs exclusively on the coccolith surface (Figure $2 \mathrm{~b}$ ). Further details regarding the nucleation procedure and the decoration of the coccoliths are provided in the Supporting Information. After being washed with ultrapure 


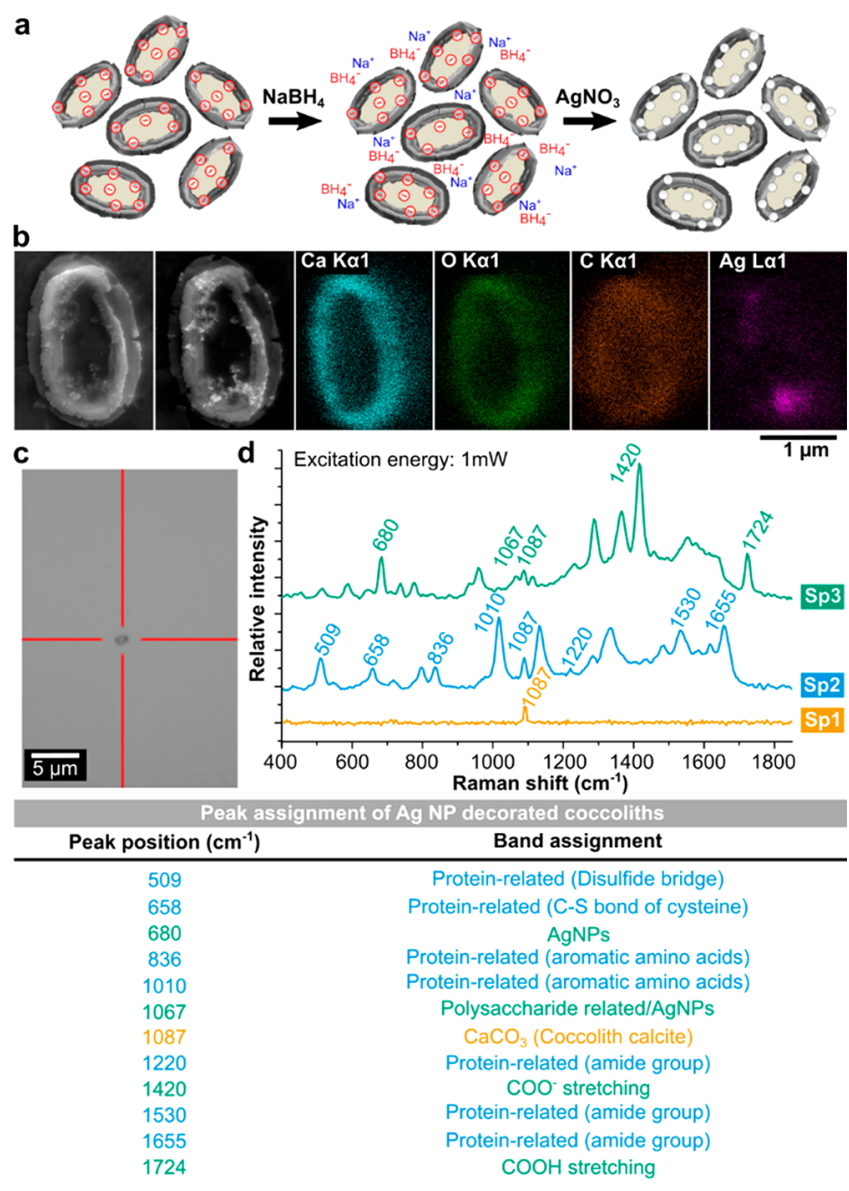

Figure 2. SERS microspectroscopy provides information about the organic matrix information from individual whole coccoliths. (a) Preparation of whole coccoliths for SERS analyses. (b) Scanning electron and EDX micrographs showing the surface of a treated $P$. carterae coccolith decorated with AgNP. The treatment preserves the coccolith calcite. In backscattered electron mode (BSE), where contrast is related to the atomic number of the element, the AgNPs appear brighter than the coccolith calcite. (c) Microscopy-guided selection of a single AgNP-decorated coccolith for SERS measurement. (d) Representative SERS spectra of natural state coccoliths (Sp1) and two individual AgNP-decorated coccoliths ( $\mathrm{Sp} 2$ and $\mathrm{Sp} 3$ ) and assignment of the Raman peaks. The difference in the two coccolith spectra reflects the different location of the AgNP on the coccolith surface contributing to the spectrum. The Sp3 spectrum shows features of polysaccharides. The second spectrum $(\mathrm{Sp} 2)$ is rich in protein-related peaks. Proteins are integral components of coccolith base plates. For detailed information about the peak assignments, see Table S3.

water, the AgNP-decorated coccoliths were spread on quartz slides and subjected to Raman microspectroscopy.

To explore the potential of the SERS technique, we acquired spectra from aggregates of coccoliths and individual coccoliths (Figure 2c). All spectra from AgNP-decorated coccoliths show peak patterns that are much more complex than those of native state coccoliths, demonstrating SERS signal enhancement. Comparison of the SERS spectra of different coccoliths revealed that they all contain the peak of $\mathrm{CaCO}_{3}(1087$ $\mathrm{cm}^{-1}$, related to symmetric stretching of the $\mathrm{C}=\mathrm{O}$ moiety in $\mathrm{CaCO}_{3}$ ) and AgNP-specific peaks ${ }^{26}$ (Figure S2) but differ in the intensity and pattern of the other peaks. The heterogeneity in the presence of the peaks and their intensity is known to arise from (i) the heterogeneity of the AgNP pattern in the focal spot of the laser and (ii) differences in the distances between the biomolecules and the AgNPs. ${ }^{27}$ It should be noted that this diversity is advantageous for obtaining a comprehensive picture of the organic matrix composition, as components may become visible, which are masked by abundant components in conventional Raman spectra. Assignment of the major peaks revealed two groups of spectra (Figure 2d). The spectra in the first group contain characteristic peaks for uronic acid-rich polysaccharides analogous to the spectra of the purified coccolith polysaccharides (Figure $1 \mathrm{c}, \mathrm{d})$. The striking features of these spectra are two peaks for unprotonated and protonated carboxylic acid groups (1420 and $\left.1724 \mathrm{~cm}^{-1}\right)$. The spectra of the second group are enriched with peaks characteristic of proteins (amide I, II, and III modes at 1655,1530 , and $1220 \mathrm{~cm}^{-1}$, respectively; aromatic modes at 1010,1593 , and $1618 \mathrm{~cm}^{-1}$; disulfide bonds at 509 and 658 $\mathrm{cm}^{-1}$ ), which are components of the coccolith base plates (Figure 1d). ${ }^{28}$ Control experiments, in which we compared the isolated soluble and insoluble organic matrix of $P$. carterae coccoliths before and after $\mathrm{NaBH}_{4}$ treatment, revealed no noticeable change in the peak pattern caused by the treatment (Figures S3 and S4).

Inspired by the recovery of macromolecules from fossil coccolith assemblages and knowing that preparing unambiguously monospecific coccolith assemblages is very difficult, ${ }^{9,14}$ we tested if our SERS approach also functions for fossil coccoliths. We used material from sediment core GeoB126131, dating back $\sim 470 \mathrm{ka}^{29}$ Scanning electron microscopy (SEM) analysis revealed coccoliths of different genera, including Calcidiscus, as well as fragments of foraminifera skeletons and particles of unknown origin (Figure 3a). We focused on the coccoliths of a Calcidiscus species because the orientation (proximal or distal shield view) of intact coccoliths can be easily identified by optical microscopy. Analogous to the results for $P$. carterae coccoliths, conventional Raman spectra of Calcidiscus coccoliths also showed exclusively calciterelated peaks (Figure S5). We therefore prepared sediment core material for SERS analysis. SEM imaging of the sediment core material after exposure to $\mathrm{NaBH}_{4}$ and $\mathrm{AgNO}_{3}$ solutions revealed randomly distributed AgNPs on the surface of the fossil coccoliths (Figure $3 \mathrm{~b}$ and Figure S6). It is noteworthy that fragments of the foraminifera skeletons lacked AgNP decoration, suggesting the absence of negatively charged organic material on the surface of the skeletal fragments.

Next, we acquired SERS spectra from Calcidiscus coccoliths from both orientations (proximal shield or distal shield in the focal plane). For each coccolith, we recorded spectra at different positions to capture as much of the available compositional information as possible (Figure S7). This was possible because the focusing spot of the objective has a diameter of $\sim 250 \mathrm{~nm}$ while the coccoliths have a diameter of $\sim 3 \mu \mathrm{m}$. All SERS spectra from the AgNP-decorated Calcidiscus sp. coccoliths show several intense peaks, including peaks characteristic of $\mathrm{CaCO}_{3}$ and AgNPs (Figure 3c). The spectra deviate from each other with respect to the peak pattern and peak intensities for the same reasons already discussed above. To obtain a well-founded picture of the organic residue of the fossil Calcidiscus coccoliths, we recorded more than 100 spectra from the distal side of 22 coccoliths and from the proximal side of 19 coccoliths and plotted the frequency of the peak appearance for the proximal side and the distal side of the coccoliths (Figure 3c,d). The plots revealed the proximal side, which is the base plate side, to show a higher frequency of peak 

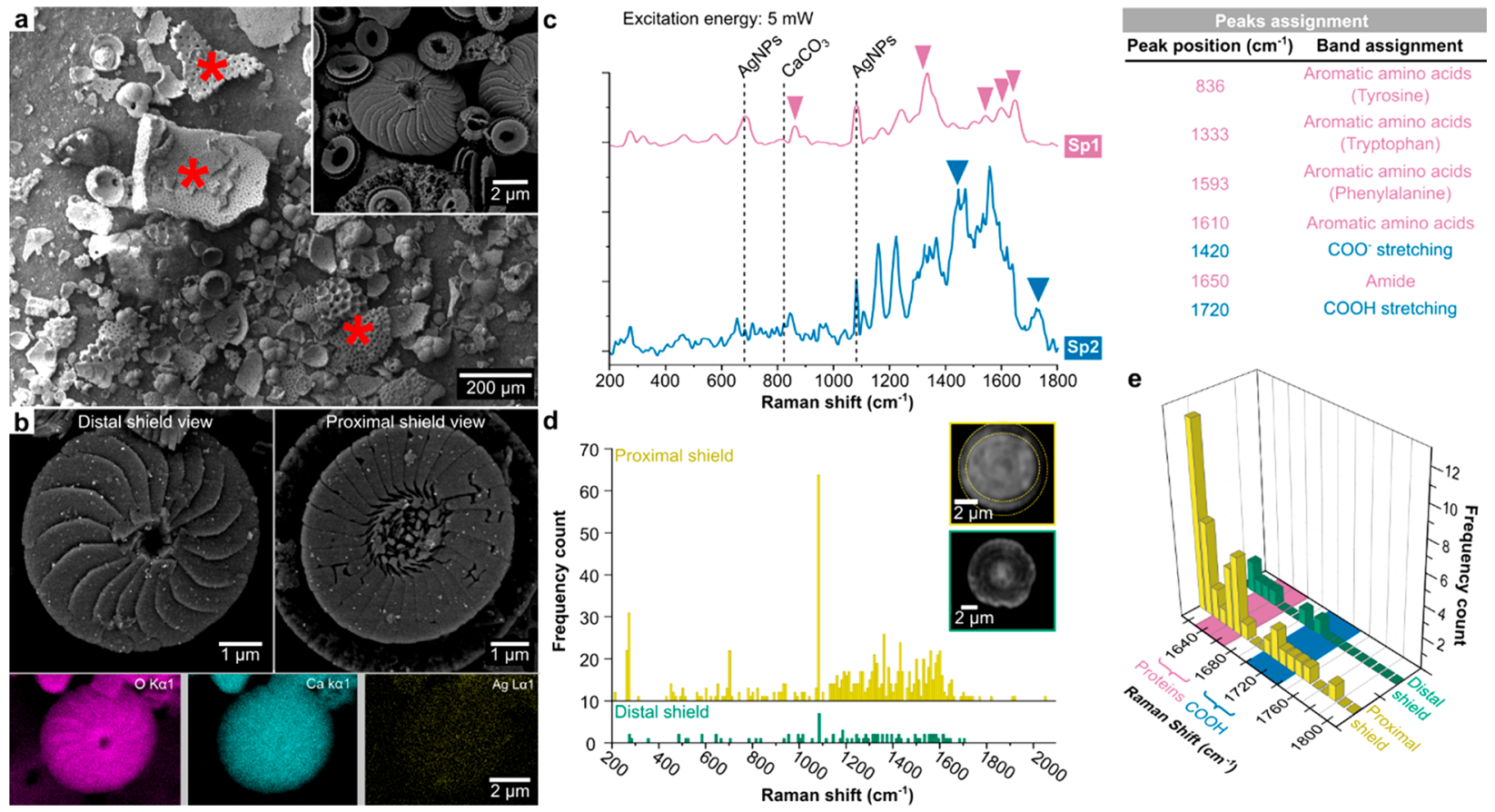

Figure 3. Analysis of a $470 \mathrm{ka}$ old calcareous nannofossil ooze sample. (a) Scanning electron micrograph of the nannofossil ooze sample showing fragments of fossil foraminifera skeletons (asterisks) and coccoliths (inset). (b) Backscattered scanning electron and EDX micrographs of fossil Calcidiscus sp. coccoliths, revealing the successful formation of AgNPs on the coccolith surface. In backscattered electron mode, the contrast is related to the atomic number of the element with the AgNPs being brighter than the coccolith calcite. The EDX micrographs show the distal shield of the same coccolith. (c) Representative SERS spectra of two individual Calcidiscus coccoliths from the calcareous nannofossil ooze sample and assignment of the Raman peaks. The Sp1 spectrum is rich in protein-related peaks, while the Sp2 spectrum shows features related to the acidic coccolith polysaccharides. (d) Histogram showing the peak frequencies in the spectra obtained from proximal and distal shields of ancient Calcidiscus coccoliths. The orientation of the coccoliths was determined using the bright field optics of the Raman microscope. The proximal side of Calcidiscus coccoliths can be identified by two concentric rings (yellow bars in the histogram). The distal side appears as a single ring with a bright center (green bars in the histogram). (e) Comparison of the region between 1600 and $1800 \mathrm{~cm}^{-1}$, highlighting differences with respect to features related to proteins (pink) and carboxylate groups (blue).

appearance than the distal side, suggesting more organic residue to be present. To determine if the proximal and distal sides are compositionally distinguishable, we analyzed all spectra for peaks characteristic of proteins and polysaccharides. As a proxy for acidic polysaccharides, which are constituents of the organic matrix of coccoliths of extant Calcidiscus species, we used carboxylate groups. The analysis revealed the spectra of the proximal coccolith side to have protein-related peaks at frequencies higher than those of acidic polysaccharide-related peaks (Figure 3e). For the distal side, however, almost all spectra lack peaks characteristic of proteins.

The difference in the abundance of protein- and acidic polysaccharide-related chemical groups between the distal and proximal coccolith side fits with the current picture of the organization of the coccolith organic matrix, which is that soluble acidic polysaccharides coat the calcite crystals and that coccolith-associated proteins are confined to the base plates. ${ }^{5,7}$ The consistency of the compositional results among the coccoliths and the marked difference between the coccoliths and foraminifera skeletons with respect to the presence of surface-associated organic material strongly suggest that the identified organic material on the coccoliths is genuinely coccolith-related and not an introduced contamination. If the latter were the case, it is very likely that the surface of foraminifera skeletons would have become contaminated, as well, which is not the case according to our data (Figure S8).

To validate our data for the fossil Calcidiscus coccoliths, we repeated the SERS measurements with coccoliths that we had isolated from fresh Calcidiscus leptoporus cultures (Figure 4). In SEM micrographs, these coccoliths show a higher degree of AgNP decoration compared to the fossil coccoliths (Figure S9). This suggests that there is more organic material on the surface of the fresh coccolith than on the surface of the fossil coccolith. Our visual impression of a higher degree of AgNP decoration was supported by the SERS measurements as a significantly lower laser power was sufficient to obtain peak intensities similar to those of the fossil coccoliths (Figures $3 c$ and $4 \mathrm{a})$. For a comparison with the data of the fossil coccoliths, we concentrated in the analysis of the spectra on features representing proteins and carboxylate residues, the latter serving as a proxy for acidic polysaccharides. For the proximal side (base plate side) of fresh coccoliths, we found peaks for acidic polysaccharides and proteins, the latter represented by features of cysteine, tyrosine, and tryptophan residues, to be equally frequent in the spectra. For the distal coccolith side, we found protein-related features to be absent in most of the spectra and acidic polysaccharide-indicative features to be present at moderate frequency. In comparison with the data of the fossil Calcidiscus coccoliths, the pattern of the feature frequencies shows the same trend for each coccolith side, supporting once more the idea that the organic material on the fossil coccoliths is ancient coccolith matrix residue.

Recent studies reported the preservation of uronic acid-rich polysaccharides in fossil coccolith assemblages and suggested that these polysaccharides could be used for paleoclimate reconstruction. ${ }^{9,14}$ In comparison to these previous studies, our 


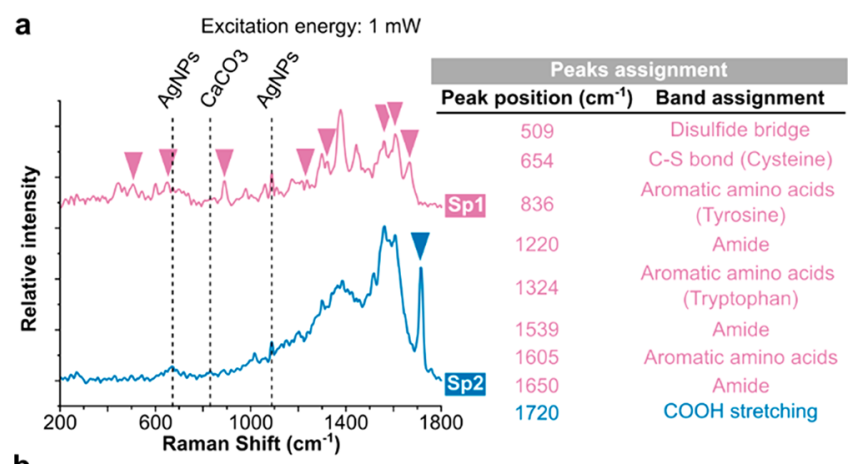

b

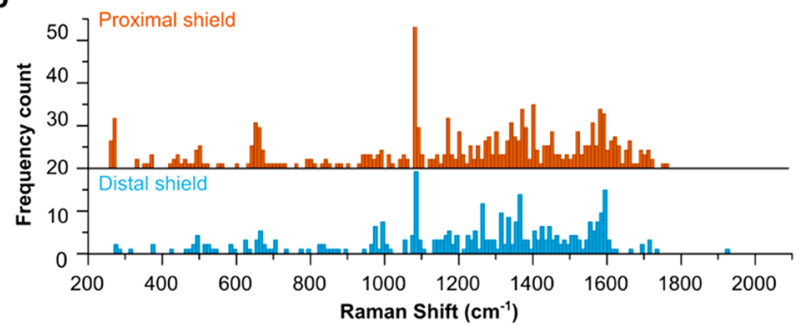

C

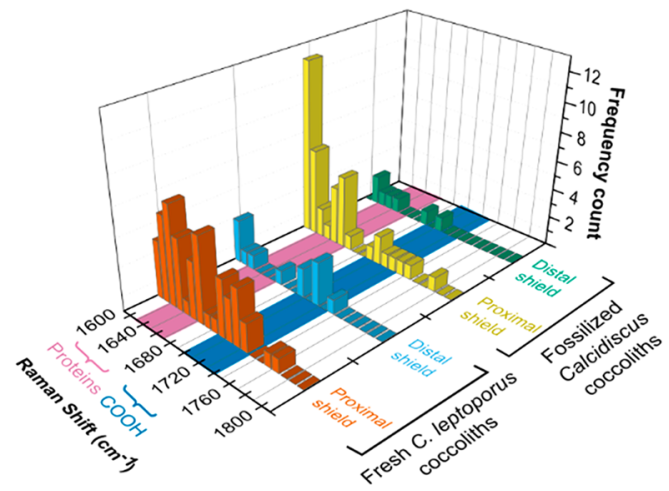

Figure 4. SERS fingerprint of $C$. leptoporus coccoliths that resembles that of the fossilized Calcidiscus sp. coccoliths. (a) Two representative SERS spectra acquired from coccoliths isolated from $C$. leptoporus cultures. The Sp1 spectrum shows protein-related peaks, and the Sp2 spectrum shows peaks arising from carboxylate groups. (b) Histogram showing the peak frequencies in the spectra obtained from proximal and distal coccolith shields. The orientation of the coccoliths has been determined using the bright field optics of the Raman microscope. (c) Comparison of the peak frequencies (in the region between 1600 and $1800 \mathrm{~cm}^{-1}$ ) between the fossilized Calcidiscus coccoliths (yellow and green) and the coccoliths of cultivated C. leptoporus (brown and light blue), with respect to features related to proteins (pink) and $\mathrm{COOH}$ groups (blue).

microscopy-assisted approach has an advantage that it allows for complete monotypic analyses and provides not only evidence for ancient acidic polysaccharides but also for the first time evidence for proteins. Calcareous microskeletons in sediments are strongly affected by taphonomical processes and exposed to contamination by unrelated organic material, which needs to be considered when interpreting biochemical data from this type of sample. Material of taxons that are extant but also present in the sedimental record provides the possibility of validating data obtained from the fossil materials, analogous to our work on Calcidiscus coccoliths. To obtain useful data sets from fossil material, it is important that a contamination of the surface of the skeletal particles can be ruled out. Uncertainties may be minimized by (i) acquiring data at different positions on each particle that is analyzed, (ii) analyzing statistically relevant numbers of particles, and (iii) including particles unrelated to those of the taxon of interest, as we did here. A common set of peaks among skeletons of the same taxon, the absence of these peaks from the spectra of coexisting skeletons of other taxa, and variation of the peak pattern for different positions at individual skeletons are the criteria that should be fulfilled for meaningful conclusions. Further work may also consider cleansing treatments of the material, but the usefulness of different treatments needs to be evaluated first. Surface cleansing treatments with $\mathrm{NaOCl}$, as are employed for cleaning fossil mollusc shells and their constituent micrometerthick crystals, ${ }^{30}$ may not be suitable for cleaning coccoliths because the constituent crystals of coccoliths are only a few nanometers thick, making it likely that even intracrystalline organic material is oxidatively degraded.

Because we have demonstrated the value of SERS microspectroscopy for characterizing the nature of organic material associated with calcareous microstructures, future studies may want to explore if additional information can be obtained by implementing modifications of the approach. The use of polarized laser light could be an interesting modification but requires the presence of anisotropic metal nanoparticles, such as wire- or rod-shaped nanoparticles, on the specimen surface. $^{23,31,32}$ Nanoparticles with such shapes can be synthesized in solution but likely not precipitated on the specimen, requiring the binding of the presynthesized particles to the specimen surface. However, this approach can complicate the spectra. The development of an approach for the semiquantitative analysis of peak intensities enabling a quantitative comparison of the spectra of different samples is another desirable direction in which future work could go. ${ }^{33}$ Currently, a semiquantitative approach would be highly ambitious because it requires uniform arrays of nanoparticles that are evenly distributed on the substrate surface. However, further developments may make the implementation of this approach possible.

The approach presented in this work closes a gap in the spectrum of technologies used for studying the calcareous structures of microscopic organisms. In cases in which only small amounts of material are available or the available material is a mixture of morphological discriminable species, SERS microspectroscopy now provides the possibility of characterizing the biomineral-associated organic material. Given the geochemical and ecological implications and nanotechnological promise of biomineralization by microscopic organisms, we expect SERS microspectroscopy to become a powerful tool in the corresponding fields of research.

\section{ASSOCIATED CONTENT}

\section{SI Supporting Information}

The Supporting Information is available free of charge at https://pubs.acs.org/doi/10.1021/acs.jpclett.0c02041.

Materials and methods and supplementary figures, including additional Raman spectra, EDX characterization of the AgNP-decorated coccoliths, SEM micrographs of fresh and fossil coccoliths after AgNP decoration, and details about the assignments of the Raman peaks (PDF)

\section{AUTHOR INFORMATION}

\section{Corresponding Authors}

André Scheffel - Max Planck Institute of Molecular Plant Physiology, 14476 Potsdam-Golm, Germany; 이이.org/ 
0000-0003-2543-1926; Email: Scheffel@mpimpgolm.mpg.de

Damien Faivre - Max Planck Institute of Colloids and Interfaces, Department of Biomaterials, 14476 Potsdam, Germany; Aix-Marseille Universite, CEA, CNRS, BIAM, 13108 Saint Paul lez Durance, France; 이이이.org/0000-00016191-3389; Email: Damien.FAIVRE@mpikg.mpg.de

\section{Authors}

Alessandro Silvestri - Max Planck Institute of Colloids and Interfaces, Department of Biomaterials, 14476 Potsdam, Germany; Max Planck Institute of Molecular Plant Physiology, 14476 Potsdam-Golm, Germany

Jürgen Pätzold - University of Bremen, MARUM-Center for Marine Environmental Sciences, 28359 Bremen, Germany

Peter Fratzl - Max Planck Institute of Colloids and Interfaces, Department of Biomaterials, 14476 Potsdam, Germany

Complete contact information is available at: https://pubs.acs.org/10.1021/acs.jpclett.0c02041

\section{Author Contributions}

A. Silvestri, A. Scheffel, P.F., and D.F. designed the research. A. Silvestri and A. Scheffel performed the research. A. Silvestri analyzed data. J.P. retrieved and prepared fossil material. A. Silvestri, D.F., and A. Scheffel wrote the paper with input from all authors.

\section{Notes}

The authors declare no competing financial interest.

\section{ACKNOWLEDGMENTS}

The authors are grateful to A. W. Skeffington for critically reading the manuscript and A. Momeni (MPI of Molecular Plant Physiology) for comments on the work. The authors thank K.-H. Baumann (University of Bremen) for support in biostratigraphic age determination by identification of Parapsectris laconosa. This research was supported by the MaxPlanck Society and the Deutsche Forschungsgemeinschaft (DFG), Grants Sche1637/4-1 to A. Scheffel and FA835/9-1 to D.F. A. Scheffel acknowledges support from the Boehringer Ingelheim Foundation.

\section{REFERENCES}

(1) Marsh, M. E. Regulation of $\mathrm{CaCO}_{3}$ formation in coccolithophores. Comp. Biochem. Physiol., Part B: Biochem. Mol. Biol. 2003, 136 (4), $743-754$.

(2) de Nooijer, L. J.; Spero, H. J.; Erez, J.; Bijma, J.; Reichart, G. J. Biomineralization in perforate foraminifera. Earth-Sci. Rev. 2014, 135, $48-58$.

(3) Borman, A. H.; de Jong, E. W.; Thierry, R.; Westbroek, P.; Bosch, L.; Gruter, M.; Kamerling, J. P. Coccolith-associated polysaccharides from cells of Emiliania huxleyi (Haptophyceae). J. Phycol. 1987, 23 (2), 118-123.

(4) Walker, J. M.; Marzec, B.; Lee, R. B. Y.; Vodrazkova, K.; Day, S. J.; Tang, C. C.; Rickaby, R. E. M.; Nudelman, F. Polymorph selectivity of coccolith-associated polysaccharides from Gephyrocapsa oceanica on calcium carbonate formation in vitro. Adv. Funct. Mater. 2019, 29, 1807168

(5) Gal, A.; Wirth, R.; Kopka, J.; Fratzl, P.; Faivre, D.; Scheffel, A. Macromolecular recognition directs calcium ions to coccolith mineralization sites. Science 2016, 353 (6299), 590-593.

(6) Hassenkam, T.; Johnsson, A.; Bechgaard, K.; Stipp, S. L. S. Tracking single coccolith dissolution with picogram resolution and implications for $\mathrm{CO}_{2}$ sequestration and ocean acidification. Proc. Natl. Acad. Sci. U. S. A. 2011, 108 (21), 8571-8576.
(7) Marsh, M. E.; Dickinson, D. P. Polyanion-mediated mineralization - mineralization in coccolithophore (Pleurochrysis carterae) variants which do not express PS2, the most abundant and acidic mineral-associated polyanion in wild-type cells. Protoplasma 1997, 199 (1-2), 9-17.

(8) Kayano, K.; Saruwatari, K.; Kogure, T.; Shiraiwa, Y. Effect of coccolith polysaccharides isolated from the coccolithophorid Emiliania huxleyi on calcite crystal formation in in vitro $\mathrm{CaCO}_{3}$ crystallization. Mar. Biotechnol. 2011, 13, 83-92.

(9) Lee, R. B. Y.; Mavridou, D. A. I.; Papadakos, G.; McClelland, H. L. O.; Rickaby, R. E. M. The uronic acid content of coccolithassociated polysaccharides provides insight into coccolithogenesis and past climate. Nat. Commun. 2016, 7, 13144.

(10) McClelland, H. L. O.; Bruggeman, J.; Hermoso, M.; Rickaby, R. E. M. The origin of carbon isotope vital effects in coccolith calcite. Nat. Commun. 2017, 8, 14511.

(11) Boeckel, B.; Baumann, K.-H. Vertical and lateral variations in coccolithophore community structure across the subtropical frontal zone in the South Atlantic Ocean. Mar Micropaleontol 2008, 67 (3), 255-273.

(12) Bown, P.; Lees, J. A.; Young, J. R. Calcareous nannoplankton evolution and diversity through time. In Coccolithophores; Thierstein, H. R., Young, J. R., Eds.; Springer: Berlin, 2004; pp 481-508.

(13) Robbins, L. L.; Brew, K. Proteins from the organic matrix of core-top and fossil planktonic foraminifera. Geochim. Cosmochim. Acta 1990, 54 (8), 2285-2292.

(14) Sand, K. K.; Pedersen, C. S.; Sjöberg, S.; Nielsen, J. W.; Makovicky, E.; Stipp, S. L. S. Biomineralization: Long-term effectiveness of polysaccharides on the growth and dissolution of calcite. Cryst. Growth Des. 2014, 14 (11), 5486-5494.

(15) Minoletti, F.; Hermoso, M.; Gressier, V. Separation of sedimentary micron-sized particles for palaeoceanography and calcareous nannoplankton biogeochemistry. Nat. Protoc. 2009, 4, 14.

(16) Akiva, A.; Neder, M.; Kahil, K.; Gavriel, R.; Pinkas, I.; Goobes, G.; Mass, T. Minerals in the pre-settled coral Stylophora pistillata crystallize via protein and ion changes. Nat. Commun. 2018, 9 (1), 1880 .

(17) DeCarlo, T. M. Characterizing coral skeleton mineralogy with Raman spectroscopy. Nat. Commun. 2018, 9 (1), 5325.

(18) Lee, K.; Wagermaier, W.; Masic, A.; Kommareddy, K. P.; Bennet, M.; Manjubala, I.; Lee, S.-W.; Park, S. B.; Cölfen, H.; Fratzl, P. Self-assembly of amorphous calcium carbonate microlens arrays. Nat. Commun. 2012, 3, 725.

(19) Jantschke, A.; Pinkas, I.; Schertel, A.; Addadi, L.; Weiner, S. Biomineralization pathways in calcifying dinoflagellates: Uptake, storage in $\mathrm{MgCaP}$-rich bodies and formation of the shell. Acta Biomater. 2020, 102, 427-439.

(20) Young, J. R.; Davis, S. A.; Bown, P. R.; Mann, S. Coccolith ultrastructure and biomineralisation. J. Struct. Biol. 1999, 126, 195215.

(21) Marsh, M. E.; Chang, D. K.; King, G. C. Isolation and characterization of a novel acidic polysaccharide containing tartrate and glyoxylate residues from the mineralized scales of a unicellular coccolithophorid alga Pleurochrysis carterae. J. Biol. Chem. 1992, 267 (28), 20507-20512.

(22) Kneipp, K.; Kneipp, H.; Itzkan, I.; Dasari, R. R.; Feld, M. S. Surface-enhanced Raman scattering and biophysics. J. Phys.: Condens. Matter 2002, 14 (18), R597.

(23) Langer, J.; Jimenez de Aberasturi, D.; Aizpurua, J.; AlvarezPuebla, R. A.; Auguié, B.; Baumberg, J. J.; Bazan, G. C.; Bell, S. E. J.; Boisen, A.; Brolo, A. G.; et al. Present and future of surface-enhanced Raman scattering. ACS Nano 2020, 14, 28-117.

(24) Jantschke, A.; Herrmann, A. K.; Lesnyak, V.; Eychmuller, A.; Brunner, E. Decoration of diatom biosilica with noble metal and semiconductor nanoparticles $(<10 \mathrm{~nm})$ : Assembly, characterization, and applications. Chem. - Asian J. 2012, 7 (1), 85-90.

(25) Cialla, D.; Rösch, R.; Möller, R.; Popp, J. SERS as analytical tool for detection of bacteria. SPIE 2007, 6633, 6633_66. 
(26) Chisanga, M.; Muhamadali, H.; Kimber, R.; Goodacre, R. Quantitative detection of isotopically enriched E. coli cells by SERS. Faraday Discuss. 2017, 205 (0), 331-343.

(27) Cardinal, M. F.; Vander Ende, E.; Hackler, R. A.; McAnally, M. O.; Stair, P. C.; Schatz, G. C.; Van Duyne, R. P. Expanding applications of SERS through versatile nanomaterials engineering. Chem. Soc. Rev. 2017, 46 (13), 3886-3903.

(28) Marzec, B.; Walker, J. M.; Panagopoulou, M.; Jhons, Y.; Clare, D.; Wheeler, A.; Shaver, M. P.; Nudelman, F. Three-dimensional architecture and surface functionality of coccolith base plates. J. Struct. Biol. 2019, 208, 127.

(29) Savoye, B.; Ridderinkhof, H.; Pätzold, J.; Schneider, R. Western Indian ocean climate and sedimentation - cruise no. M75- 29 December 2007-8 April 2008 - Port Louis (Mauritius) - Cape Town (South Africa). METEOR-Berichte 2013, 196.

(30) Dauphin, Y. Fossil organic matrices of the Callovian aragonitic ammonites from Lukow (Poland): location and composition. Int. J. Earth Sci. 2002, 91 (6), 1071-1080.

(31) Etchegoin, P. G.; Galloway, C.; Le Ru, E. C. Polarizationdependent effects in surface-enhanced Raman scattering (SERS). Phys. Chem. Chem. Phys. 2006, 8 (22), 2624-2628.

(32) Masic, A.; Bertinetti, L.; Schuetz, R.; Galvis, L.; Timofeeva, N.; Dunlop, J. W. C.; Seto, J.; Hartmann, M. A.; Fratzl, P. Observations of multiscale, stress-induced changes of collagen orientation in tendon by polarized Raman spectroscopy. Biomacromolecules 2011, 12 (11), 3989-3996.

(33) Bennet, M.; Akiva, A.; Faivre, D.; Malkinson, G.; Yaniv, K.; Abdelilah-Seyfried, S.; Fratzl, P.; Masic, A. Simultaneous Raman microspectroscopy and fluorescence imaging of bone mineralization in living zebrafish larvae. Biophys. J. 2014, 106 (4), L17-L19. 